International Review of Research in Open and Distributed Learning Volume 21, Number 1

January - 2020

\title{
Editorial - Volume 21, Issue 1
}

\section{Constance Blomgren}

Associate Editor, Athabasca University

Welcome to my first editorial, the new year, and a new decade. This first issue of 2020 provides an array of research dissemination, literature reviews, field notes, and a book review. Additionally, this issue marks the recent, unanimous UNESCO Recommendation on OER adoption at the $40^{\text {th }}$ General Conference. This OER Recommendation supports the UN's Sustainable Development Goal 4 (quality education) and further enables the achievement of the other 16 development goals. UNESCO recommendations occur infrequently, and this commitment lays a firm foundation for renewed national educational system vigour through the economies of scale that openness in education provides.

Moving from this global view, IRRODL readers may consider the following articles as part of their professional learning in this new year. There are five research articles that cover the topics of MOOCs, OER textbooks, and aspects of online learning. The first article, "Studying Learner Behavior in Online Courses With Free-Certificate Coupons: Results From Two Case Studies," provides research results that examines the role of incentives and MOOCs. As pricing models for MOOCs are still evolving, these case studies examine pricing structures and the effects upon learners' participation and the manner in which they participate. This research by Littenberg-Tobias, Ruipérez-Valiente, and Reich reveals that both price elasticity and commitment through a certificate track contributed to the case study results.

"The Relationships Between Self-Efficacy, Task Value, and Self-Regulated Learning Strategies in Massive Open Online Courses" is a quantitative study that furthers the understanding of student learning within a MOOC. Lee, Watson, and Watson apply a social cognitive perspective to learning within a small MOOC that revealed both self-efficacy and task value are significant predictors of students' self-regulated learning strategies. A statistically significant difference also occurred in the use of self-regulated learning strategies between students possessing low and high self-efficacy. The authors also discovered statistical significance among self-regulated learning scores and task value.

Anderson and Cuttler provide a perception comparison of open and conventional psychology textbooks by both online and on-campus university students. The results uncovered student offsetting cost strategies, reading preferences in textbook formats (print versus digital versus both when cost is not a factor) and differences in their ratings of the importance of various textbook elements (immediate access, price, etc.).The results also indicate a preference for open digital textbooks over paid printed textbooks, not only related to the cost. "Open to Open? An Exploration of Textbook Preferences and Strategies to Offset Textbook Costs for Online Versus On-Campus Students" provides suggestions for future research in this area of the benefits and consequences of using open textbooks within higher education. 
The next study examines correlational factors of online $\mathrm{PhD}$ students technological and relational subfactors as they relate to the student success subfactors of persistence, successful completion, and gains in knowledge and skills. The results provide descriptive statistics, and the predictability and effects of technological and relational factors upon doctoral success. Lee, Chang, and Bryan's “Doctoral Students' Learning Success in Online-Based Leadership Programs: Intersection with Technological and Relational Factors" concludes with a discussion of the role of relational connectedness within educational leadership doctoral programs.

And lastly, Duran's phenomenological study, “Distance Learners' Experiences of Silence Online: A Phenomenological Inquiry," explores silence online as a lived experience. Her study reveals a complex understanding of such silence, in part enacted purposefully, and illuminating that online silence and voice may coexist. This research helps to reframe the role of online silence and its significance for learners and educators alike.

Populating our Research Notes is a study completed by Risquez, McAvinia, Desmond, Bruen, Ryan, and Coughlan that interviewed Irish higher education OER stakeholders. They inquired about the move from the previous national repository to a decentralized model that relies on institutional research repositories. Applying a mixed methods approach, these researchers share the findings of the surveys and focus groups. Participants identified present challenges to this devolved model and the researchers suggest a blended approach to repository use. The article, "Towards a Devolved Model of Management of OER? The Case of the Irish Higher Education Sector," provides a thoughtful look at OER management as part of the unfolding of openness in education.

For this first issue of the new decade, two literature reviews have been included. The first review, "Open and Shut: Open Access in Hybrid Educational Technology J ournals 2010 - 2017," examines a 7-year span and included over 8,400 journal articles. Costello, Farrelly, and Murphy's meta-analysis reveals that research behind paywalls continues to be firmly in place and that open access publishing continues to be seldom pursued by scholars. Additionally, complexity and costs of legal open access publishing may be constraining the accessibility of research dissemination. For the second review, Fiock created helpful tables to present literature findings in "Designing a Community of Inquiry in Online Courses." When considering the cognitive, teaching, and social presences as part of an online course, instructional designers and online educators will appreciate Fiock's table design ease that she has populated with numerous research insights.

There are also two contributions to our Notes From the Field section. Clements, West, and Hunsaker provide answers to microcreditial questions ranging from how to get started with open badges to the technologies that assist with such initiatives. Based on the history of badges and experiences with such microcreditials, the authors provide a framework and guiding steps to support the implementation of open badges. The authors certainly answer many implementation questions in "Getting Started with Open Badges and Open Microcredentials." The second contribution provides a design framework and best practices, both pedagogical and within an institution, of adaptive courseware, adaptive learning and learning analytics. The inclusion of screenshots further the points made by Cavanagh, Chen, Lahcen, and Paradiso in the field note "Constructing a Design Framework and Pedagogical Approach for Adaptive Learning in Higher Education: A Practitioner's Perspective." 
Book reviews provide a helpful synopsis of recent publications, and Faulconer penned her thoughts of the edited book, High-Impact Practices in Online Education. As an online instructor and scholar of learning and teaching, her summary and comments enable IRRODL readers the opportunity to consider the merits of this new contribution to the pedagogy of online education.

I encourage you to delve in and explore this newest issue from IRRODL.

\section{Athabasca}

University

(c) (†) 